This is the author's final, peer-reviewed manuscript as accepted for publication. The publisher-formatted version may be available through the publisher's web site or your institution's library.

\title{
The effects of short-term fish oil supplementation on pulmonary function and airway inflammation following a high-fat meal
}

Carl J. Ade · S. K. Rosenkranz · C. A. Harms

\section{How to cite this manuscript}

If you make reference to this version of the manuscript, use the following information:

Ade, C. J., Rosenkranz, S. K., \& Harms, C. A. (2014). The effects of short-term fish oil supplementation on pulmonary function and airway inflammation following a high-fat meal. Retrieved from http://krex.ksu.edu

\section{Published Version Information}

Citation: Ade, C. J., Rosenkranz, S. K., \& Harms, C. A. (2014). The effects of shortterm fish oil supplementation on pulmonary function and airway inflammation following a high-fat meal. European journal of applied physiology, 114(4), 675-682.

Copyright: ( ) Springer-Verlag Berlin Heidelberg 2013

Digital Object Identifier (DOI):10.1007/s00421-013-2792-7

Publisher's Link: http://link.springer.com/article/10.1007/s00421-013-2792-7

This item was retrieved from the K-State Research Exchange (K-REx), the institutional repository of Kansas State University. K-REx is available at http://krex.ksu.edu 


\section{The effects of short-term fish oil supplementation on pulmonary function and airway inflammation following a high fat meal}

Ade, C.J. (1,2), Rosenkranz, S.K (3), Harms C.A. (1)

(1) Department of Kinesiology, Kansas State University, Manhattan, KS, USA

(2) Department of Anatomy and Physiology, Kansas State University, Manhattan, KS, USA

(3) Department of Human Nutrition, Kansas State University, Manhattan, KS, USA

Key Words: Airway inflammation; High-fat; Fish-oil; Pulmonary function

Address for correspondence

Carl J. Ade, M.S.

Department of Kinesiology

Kansas State University, 1A Natatorium, Manhattan, KS, 66502

Tel: $785-577-4098$

E-mail: cade@k-state.edu

We are submitting an original article titled: The effects of short-term fish oil supplementation on pulmonary function and airway inflammation following a high fat meal. We state that this manuscript is not under consideration elsewhere and that the research reported will not be submitted for publication elsewhere until a final decision is made as to the acceptability of the manuscript. There is no financial or other relationship that influenced the outcome of this paper. In addition, this manuscript represents original work without fabrication, fraud or plagiarism and has been read and approved by all authors. 


\section{ABSTRACT}

Many environmental and dietary influences can cause immune cells to produce biological mediators that increase airway inflammation. A high-fat meal (HFM) is one stimulus that increases airway inflammation in healthy individuals. Supplementation with omega-3 fatty acids can reduce inflammation systemically and may be beneficial to the airways. Purpose: To determine if omega-3 fatty acid supplementation via fish oil would mitigate the airway inflammatory response induced by a single HFM. Methods: Seventeen non-asthmatic men (22 \pm

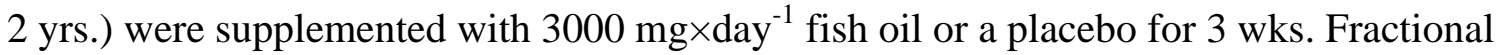
exhaled nitric oxide ( $\mathrm{FE}_{\mathrm{NO}}$; a marker of airway inflammation), impulse oscillometry (a measure of respiratory impedance), pulmonary function, and triglycerides were measured prior to and two hours following a HFM. Results: Following a HFM, triglycerides increased in both fish oil and placebo groups compared to pre-HFM ( $\sim 59 \%$ and $\sim 49 \%$ respectively, $\mathrm{p}<0.05)$. The percent increase in $\mathrm{FE}_{\mathrm{NO}}$ was greater in the placebo group compared to the fish oil group $(25.7 \pm 16.7 \%$ vs. $-1.99 \pm 10.5 \%$ respectively, $\mathrm{p}<0.05$ ). A significant correlation was observed between blood triglycerides and $\mathrm{FE}_{\mathrm{NO}}$ in the placebo group $(\mathrm{r}=0.61 ; \mathrm{p}<0.05)$, but not the fish oil group ( $p=0.21)$.Conclusion: A single HFM increases airway inflammation and omega-3 fatty acid supplementation via fish oil protects against HFM associated changes in airway health. 


\section{INTRODUCTION}

Systemic and localized inflammation is triggered by physical injury, microorganisms, chemical toxins, and hypersensitivity (Sherwood 2001). These biological responses are associated with increased production and release of inflammatory mediators from the blood plasma, white blood

cells, mast cells, and endothelium all of which contribute to a cascade of additional inflammatory processes (Sherwood 2001). In addition, long-term exposure to inflammation is linked with an increased risk of several disorders, including atherosclerosis, reheumatoid arthritis, inflammatory bowel syndrome, asthma, and adult respiratory distress syndrome (Calder 2003; Libby et al. 2002).

One recently discovered and often overlooked inflammatory trigger is the nutritional content of our diet. Van Oostrom et al. (2003) was one of the first to demonstrate that a single high-fat meal (HFM) containing 40\% weight/volume fat emulsion increased monocyte and neutrophil count, suggesting onset of an inflammatory response. This type of single meal was also used to reveal an association between high blood triglycerides and glucose levels and the production of proinflammatory cytokines and oxidative stress (Eriksson et al. 2001; van Oostrom et al. 2003). In addition, the recent findings of Rosenkranz et al. (2010) in our laboratory demonstrated for the first time that a HFM significantly increased both blood triglycerides and airway inflammation in healthy men and women. Thus it becomes evident that some component of dietary fat intake elicits an inflammatory response that can be observed both systemically and within the pulmonary system. 
Emergent evidence suggests that omega-6 fatty acids are a primary mechanism mediating the inflammatory response observed with high fat diets (Galland 2010). Furthermore, regular intake of a pro-inflammatory diet, primarily one including omega-6 fatty acids, is often associated with increases in the prevalence of pulmonary distress. The typical western diet often contains disproportionately high omega-6 content relative to the omega-3 fatty acids (Simopoulos 2002; Simopoulos 2008). As such, individuals from populations traditionally with this type of diet have a high percentage of the omega- 6 fatty acid arachidonic acid and very low fractions of the omega-3 fatty acid eicosapentaenoic acid (EPA) within their inflammatory cells (Gibney and Hunter 1993; Sperling et al. 1993). However, dietary supplementation with omega-3 fatty acids increases the fraction of omega-3s EPA and docosahezaenoic acid (DHA) within the plasma membrane of cells (De Caterina et al. 1994; Kew et al. 2004; Meydani et al. 1993; Mickleborough et al. 2006; Mickleborough et al. 2003; Sperling et al. 1993) which subsequently produces less biologically active inflammatory mediators (Calder 2003; Obata et al. 1999).

The omega-3 fatty acids EPA and DHA can be derived from a variety of sources including marine or fish oil (Whelan and Rust 2006). As such significant associations between fish intake and lung function suggest that omega-3 fatty acids may have a beneficial influence on pulmonary physiology (Laerum et al. 2007; Schwartz and Weiss 1994). Mickleborough and colleagues have demonstrated the protective effects of fish oil on exercise induced bronchoconstriction in asthmatic populations (Mickleborough et al. 2006; Mickleborough et al. 2003). In addition, Tecklenburg-Lund et al. (2010) reduced airway inflammation in asthmatic subjects following a 
3wk period of fish oil supplementation (Tecklenburg-Lund et al. 2010). However, to date, it is unknown if fish oil supplementation for a similar 3 wk period will mitigate the airway inflammatory response elicited by a single HFM.

The rationale for the present study was that because omega-3 fatty acids, and by extension fish oil, has a systemic anti-inflammatory action, airway inflammation following a HFM would be reduced. It was hypothesized that (i) a single HFM would increase post-prandial airway inflammation, (ii) a linear relationship would exists between blood triglycerides and airway inflammation, and (iii) that 3 wks fish oil supplementation would prevent the HFM post-prandial increase in airway inflammation.

\section{MATERIALS AND METHODS}

\section{Subjects}

Seventeen men (age $22 \pm 2$ yrs (mean \pm SD)) completed the experiments. All subjects had no history of cardiovascular, pulmonary, or metabolic disease and were non-smokers as determined from medial history questionnaire. Of the subjects none were regularly using anti-oxidant supplements or anti-inflammatory drugs. Subjects were excluded if using bronchial dilators, lipid lowering medication, or fish oil supplements. Subject’s dietary habits were not directly monitored prior to or during the study period, but were continuously instructed to not change their diet or physical activity habits. Verbal and written consent was obtained from all subjects. 
The study was approved by the Institutional Review Board for Research Involving Human Subjects at Kansas State University, and conformed to the Decleration of Helsenki.

\section{Experimental Design}

This study was conducted as a randomized, single blinded trial. Following pre-trial testing (i.e., baseline), each subject was randomly assigned to three weeks of either a fish oil supplementation condition or a placebo condition. Subjects in the placebo condition continued their normal diet plus three similar appearing capsules containing room air. In the fish oil condition; subjects continued their normal diet plus three capsules per day containing $1000 \mathrm{mg}$ of fish oil each (containing 180 mg EPA and 120 mg DHA; Spring Valley Omega-3 Fish Oil, Springfield MO). The reported EPA and DHA contents by the manufacture were not verified prior to the study but have been previously reported elsewhere (Harris 2004; Juturu 2008). Subjects were instructed to take the pills each day of the experimental period and were asked not to eat fish during the course of the study and were contacted regularly to inquire about any adverse reactions and to monitor compliance. Subjects visited the laboratory after an overnight fast (12 h) and abstaining from exercise (24 h) following the $3 \mathrm{wk}$ supplementation period (Pre-HFM) and $2 \mathrm{~h}$ following the consumption of a HFM (Post-HFM). At each session, resting measurements of pulmonary function, airway impedance, fractional exhaled nitric oxide, and blood triglycerides were made.

The "over-the-counter" HFM used in the present study was identical to that previously employed by Rosenkranz et al. (2010). The meal consisted of a fat dose equivalent to $1 \mathrm{~g}$ fat per $\mathrm{kg}$ bodyweight and was composed of ice cream (Edy's Grand Vanilla) and whipping cream (Reddi 
wip original). Ice cream serving size was measured as $\mathrm{ml}$ of ice cream $=$ bodyweight in $\mathrm{kg} \times$ 4.0625. Whipping cream was measured as $\mathrm{ml}$ of whipped cream $=$ bodyweight in $\mathrm{kg} \times 1.5$. The nutritional makeup of the HFM was $4.5 \mathrm{~g}$ saturated fat (39.8-56.9 g) per serving, $30 \mathrm{mg}$ cholesterol (339.7-485.5 mg) per serving, and $16 \mathrm{~g}$ of carbohydrate (106.7-152.5 g) per serving. The meal was ingested within $20 \mathrm{~min}$.

\section{Experimental Measurements}

Pulmonary function was assessed via standard measurements of peak expiratory flow (PEF), forced expiratory flow in 1-sec $\left(\mathrm{FEV}_{1}\right)$, forced expiratory flow at $25-75 \%$ of vital capacity ( $\mathrm{FEF}_{25-75}$ ), and forced vital capacity (FVC) (SensorMedics 229 Metabolic Cart, SensorMedics Corp, Yorba Linda, CA, USA) according to the manufactures guidelines and the American Thoracic Society criteria of pulmonary function testing. As such, the highest values from the three repeated trials were recorded. Airway impedance was measured using a commercially available airway oscillometry system (IOS, Jaeger, Germany) (Vink Pediat Pulmon 2003) according to the manufactures guidelines. This system measures impedance $(\mathrm{Z})$ of the total respiratory system, from which calculations of resistance $(\mathrm{R})$ and reactance $(\mathrm{X})$ can be made. In

the present study Z, R, and X were measured across a frequency range of 5-35 Hz. The averages of three repeated trials were recorded. Airway inflammation was evaluated using measurements of fractional exhaled nitric oxide $\left(\mathrm{FE}_{\mathrm{NO}}\right)$ via chemiluminescence (Sievers Nitric Oxide Analyzer 280, Sievers Instruments Inc, Boulder, CO, USA) in accordance to the manufactures guidelines and the American Thoracic Society recommendations. FE $E_{N O}$ provides reproducible and noninvasive assessment of inflammation in the lower-respiratory tract (Gabbay et al. 1998). Briefly, 
while wearing a nose piece to prevent contributions of nasal NO, subjects were asked to inhale orally to total lung capacity and then immediately perform a constant and controlled exhalation flow rate to vital capacity into a rapid NO analyzer. The averages of three repeated trials, all within $5 \%$ of the mean value, were recorded. A minimum of 30 seconds of relaxed breathing was given between trials. Measurements of total cholesterol and triglycerides were determined from a finger-stick blood sample and analyzed via an automated lipid analyzer (Cholestech, LDX). Measurements of respiratory impedance and blood lipids were not completed in 4 subjects due to equipment unavailability (2, fish oil; 2, placebo). Subjects were in a seated position for all experimental measurements.

\section{Statistical Analysis}

Data are given as mean \pm SD except when otherwise stated. The impact of fish oil supplementation (or placebo) and a HFM post-prandial response were tested by two-way repeated measures ANOVA with a Newman-Keuls test as a post hoc analysis test. Linear correlation analysis was used to assess the relationship between blood triglycerides and airway inflammation across individuals in the placebo and fish oil groups. Significance was set at p < 0.05 for all analyses.

\section{RESULTS}

\section{Baseline Characteristics}


General subject characteristics and pulmonary function measurements at baseline are shown in Table 1. Stature and body mass were not significantly different between fish oil and placebo conditions. At baseline standard pulmonary function measurements, FENO respiratory impedance, and blood lipids were not significantly different between experimental groups. However, baseline $\mathrm{FE}_{\mathrm{NO}}$ varied by approximately $30 \mathrm{ppb}$ across subjects and may reflect the varied caloric and nutritional dietary habits in college aged men.

\section{Standard pulmonary function and Impedance}

Following a HFM, triglycerides significantly increased in both fish oil and placebo groups compared to pre-HFM (59\% and 49\% respectively). Standard pulmonary function test and respiratory impedance test values pre and post-HFM are shown in Table 2. Pre-HFM values of $\mathrm{PEF}, \mathrm{FEF}_{25-75}$, and $\mathrm{FEV}_{1}$ were not different between experimental groups. In addition, these variables were unchanged ( $\mathrm{p}>0.05)$ post-HFM compared to pre in both groups. Similar to standard pulmonary function variables, measurements of respiratory impedance were similar between experimental groups pre-HFM and were unchanged post-HFM.

\section{Exhaled nitric oxide}

Figure 1 illustrates the individual and group mean change in $\mathrm{FE}_{\mathrm{NO}}$ before and after HFM. In the placebo group, post-HFM FE $\mathrm{N}_{\mathrm{NO}}$ significantly increased in 9 of 9 subjects by approximately $4 \mathrm{ppb}$ (range: 0.6-11.2) compared to pre-HFM. In the fish oil group, post-HFM FE $E_{N O}$ did not appreciably change compared to pre-HFM ( $\mathrm{p}>0.05$ ). In this group, 2 of 8 subjects demonstrated a 
less than 1.0 ppb elevation in FE ${ }_{N O}$ compared to pre-HFM. The percent change in FENO from preHFM was significantly less in the fish oil group compared to the placebo group (-1.99 $\pm 3.97 \%$ versus $25.7 \pm 35.93 \%$ respectively). Figure 2 illustrates the significant association between blood triglycerides and $\mathrm{FE}_{\mathrm{NO}}$ in the placebo group pre and post-HFM ( $\left.\mathrm{r}=0.61, \mathrm{p}<0.05\right)$. However, the regression relating triglycerides and $\mathrm{FE}_{\mathrm{NO}}$ for the fish oil group was not significant $(\mathrm{r}=0.39$, $\mathrm{p}=0.21)$.

\section{DISCUSSION}

The primary findings of the present study are that omega-3 fatty acid supplementation has a postprandial anti-inflammatory effect within the pulmonary system and that a significant relationship exists between blood triglycerides and airway inflammation. These findings are consistent with our first and second hypotheses that a single HFM increases airway inflammation and that its increase is associated with triglyceride levels. The third hypothesis was also well supported by the data. Three weeks of moderate omega-3 fatty acid supplementation via fish oil mitigated the airway inflammatory response following an "over-the-counter” HFM. Taken together these observations increase our understanding of the relationship between dietary fat intake and provide new insight into the anti-inflammatory effects of fish oil within the pulmonary system.

The findings of the present study extend those reported in previous investigations in our laboratory. Using FE $E_{\mathrm{NO}}$ as a biological marker of airway inflammation, Rosenkranz et al. (2010) determined that a single HFM increases airway inflammation in non-asthmatic subjects. The present study both confirms these findings and extends them by demonstrating a significant 
linear relationship between blood triglycerides and $\mathrm{FE}_{\mathrm{NO}}$. In addition, the present study demonstrates that this relationship is abolished when subjects are supplemented with dietary fish oil. These findings advocate that fish oil supplementation has positive implications in healthy individuals under dietary induced airway inflammation.

Many food substances induce inflammatory responses following consumption. High fat intake (particularly omega-6 fatty acids) is one such substance that can cause and inflammatory reaction and since the typical Western diet contains an omega-6/omega-3 ratio greater than 15/1 many individuals may be exposed to a pro-inflammatory diet (Simopoulos 2008; Simopoulos 2002). van Oostrom et al. (2004) has recently demonstrated that a single meal consisting of fresh cream elicits a mild inflammatory response (van Oostrom et al. 2004). Likewise, increases in triglycerides and glucose have been shown to be paralleled by the increased production of proinflammatory cytokines and oxidative stress (Eriksson et al. 2001; van Oostrom et al. 2003).

In adults and children, high margarine intake, a substance containing high amounts of omega-6 fatty acids, has been associated with an increased likelihood of pulmonary distress (Foliaki et al. 2008; Nagel and Linseisen 2005). Similarly, Rosenkranz et al. (2010) and the current study's placebo group demonstrate that a single HFM increases airway inflammation, but does not impact lung volumes or airway reactivity. While the mechanism defining the relationship between fat intake and airway inflammation is not well defined, one potential mediator may be the fatty acid content of inflammatory cells within the pulmonary system. A Western diet containing a high omega-6/omega-3 fatty acid ratio increases the percentage of arachidonic acid in the membrane of inflammatory cells and is linked to an increased incidence of asthma (Black 
and Sharpe 1997; Simopoulos 2002; Simopoulos 2008). When present in high amounts arachidonic acid becomes the primary substrate used in the synthesis of bioactive mediators and cytokines (Calder 2001). Therefore, the HFM induced acute inflammatory response reported by Rosenkranz et al. (2010), Van Ostroom et al. (2004) and that of the placebo group in the current study may be the result of high arachidonic acid content in the pulmonary system. However, these conclusions are only speculative as the present study did not measure changes in the fatty acid content of systemic inflammatory or pulmonary cells.

Blood lipoprotein properties may also contribute to the HFM induced inflammation. Nichols et al. (2006) demonstrated that a high saturated fat meal decreases the anti-inflammatory properties of high-density lipoproteins (HDL) (Nicholls et al. 2006). Similarly, Patel et al. (2009) acutely induced hypertriglyceridaemia causing the formation of triglyceride-enriched HDL, which reduced HDL's anti-inflammatory properties (Patel et al. 2009). In the present study, the significant relationship between triglycerides and airway inflammation reveals that blood lipoproteins may explain in part the negative impact of high-fat intake on airway health.

Dietary supplementation with omega-3 fatty acids has a positive influence on inflammatory membrane composition and function. Two omega-3 fatty acids, EPA and DHA can replace arachidonic acid in the plasma membrane of inflammatory cells (Gibney and Hunter 1993; Sperling et al. 1993; Endres et al. 1989; Lee et al. 1985; De Caterina et al. 1994; Meydani et al. 1993; Mickleborough et al. 2006) and competitively inhibit arachidonic acid metabolism (Endres et al. 1989; Lee et al. 1985; Obata et al. 1999). Individuals experimentally supplemented with 
fish oil capsules or fed a controlled high-fish diet demonstrate a decreased capacity to produce several inflammatory mediators (Caughey et al. 1996; Endres et al. 1989; Gallai et al. 1995; Kinsella et al. 1990; Lewis et al. 1990; Meydani et al. 1993; Sadeghi et al. 1999).

Dietary fish intake is associated with increased pulmonary function and decreased risk of asthma and asthma-like symptoms (Laerum et al. 2007; Miyamoto et al. 2007; Schwartz and Weiss 1994). Biltagi et al. (2009) demonstrated that 6 weeks of omega-3 fatty acid supplementation in asthmatic children significantly reduced sputum markers of airway inflammation with a concomitant improvement in lung function (Biltagi et al. 2009). Likewise, Mickleborough and colleagues $(2003,2006)$ determined that 3 weeks of dietary omega-3 fatty acid supplementation decreases the severity of exercise-induced bronchoconstriction (EIB) in both healthy and asthmatic athletes (Mickleborough et al. 2006; Mickleborough et al. 2003). Furthermore, lower pre- and post-exercise inflammatory markers in the omega-3 supplement group compared to placebo diets paralleled the changes in EIB severity. These findings of Biltagi et al (2009) and Mickelborough et al. $(2003,2006)$, in combination with the present study, demonstrate the broad effectiveness of omega-3 fatty acid supplementation on airway inflammation in the healthy and diseased lung when exposed to inflammatory stress.

\section{Limitations}

Previous investigations report an association between airway inflammation and airway hyperresponsiveness in asthmatic patients (Hancox et al. 2007; Porsbjerg et al. 2009; Rasmussen et al. 
2009). However, the current study did not evaluate airway hyper-responsiveness, only measurements of resting pulmonary function and airway impedance. Accurate assessment of airway hyper-responsiveness would have required the introduction of a spasmogen, such as Methacholine, saline, or exercise. In addition, dietary habits were not monitored prior to or during the supplementation period. These unmonitored and uncontrolled dietary habits prior to the study period may have contributed to the variability in baseline measurements of $\mathrm{FE}_{\mathrm{NO}}$ and blood triglycerides reported in Table 1 . However, participants were repeatedly instructed throughout the study period not to change their diet and were excluded from participation if they consumed fish oil within 2 months prior to the study. Similarly, the EPA and DHA contents of the fish oil supplementation were not verified prior to the study. Variability of the omega-3 fatty acid content may have contributed to the variability in $\mathrm{FE}_{\mathrm{NO}}$ responses in the supplement group. The results of this study, therefore, are attributed to the dose of fish oil prescribed and not the specific EPA and DHA contents reported by the manufacture.

Blood triglycerides are increased by the consumption of both fats and carbohydrates. Abbasi et al. (2000) demonstrated that a 2-week low-fat, high-carbohydrate diet increases plasma triglycerides (Abbasi et al. 2000). These data suggest that the HFM used in the current study and that of Rosenkranz et al. (2010) may have been the result of a high carbohydrate intake (16 g carbohydrate per serving). However, Ahuga et al. (2009) reports that a single low-fat, highcarbohydrate meal does not significantly alter blood triglyceride levels (Ahuja et al. 2009). This data suggests that acute consumption of carbohydrates does not contribute to increased blood triglyceride levels and therefore the post-prandial triglyceride levels observed in the current study are attributed primarily to the fat content of the HFM. 
Conclusion and Relevance

In conclusion, the present study demonstrates for the first time that omega-3 fatty acid supplementation mitigates the airway inflammatory response induced by a single HFM. The key implications of the present study are twofold. First, the current study in parallel with that of Rosenkranz et al. (2010) demonstrate that the healthy airway is sensitive to acute dietary fat intake. This information provides insight into the pulmonary inflammatory response, which is often only studied in clinical populations. Secondly, the results of the current study suggest that only short-term supplementation with a moderate (3000 mg/day) dose of capsulated fish oil is required to attenuate the HFM induced airway inflammatory response. Conversely, the HFM stimulus used in the current study had no influence on resting pulmonary function. These findings suggest that individuals chronically exposed to a high-fat diet may be at an increased risk for pulmonary inflammation, but that short-term dietary supplementation with fish oil may mitigate these responses. Future studies should focus on determining the potential beneficial effects of fish oil supplementation on chronic high-fat consumption and pulmonary health. 


\section{REFERENCES}

Abbasi F, McLaughlin T, Lamendola C, Kim HS, Tanaka A, Wang T, Nakajima K, Reaven GM (2000) High carbohydrate diets, triglyceride-rich lipoproteins, and coronary heart disease risk. Am J Cardiol 85 (1):45-48. doi:S0002-9149(99)00604-9 [pii]

Ahuja KD, Adams MJ, Robertson IK, Ball MJ (2009) Acute effect of a high-carbohydrate lowfat meal on platelet aggregation. Platelets 20 (8):606-609.

doi:10.3109/09537100903267517

Biltagi MA, Baset AA, Bassiouny M, Kasrawi MA, Attia M (2009) Omega-3 fatty acids, vitamin $\mathrm{C}$ and $\mathrm{Zn}$ supplementation in asthmatic children: a randomized self-controlled study. Acta Paediatr 98 (4):737-742. doi:APA1213 [pii]

Black PN, Sharpe S (1997) Dietary fat and asthma: is there a connection? Eur Respir J 10 (1):612

Calder PC (2001) Polyunsaturated fatty acids, inflammation, and immunity. Lipids 36 (9):10071024

Calder PC (2003) N-3 polyunsaturated fatty acids and inflammation: from molecular biology to the clinic. Lipids 38 (4):343-352

Caughey GE, Mantzioris E, Gibson RA, Cleland LG, James MJ (1996) The effect on human tumor necrosis factor alpha and interleukin 1 beta production of diets enriched in n-3 fatty acids from vegetable oil or fish oil. Am J Clin Nutr 63 (1):116-122

De Caterina R, Cybulsky MI, Clinton SK, Gimbrone MA, Jr., Libby P (1994) The omega-3 fatty acid docosahexaenoate reduces cytokine-induced expression of proatherogenic and proinflammatory proteins in human endothelial cells. Arterioscler Thromb 14 (11):18291836

Endres S, Ghorbani R, Kelley VE, Georgilis K, Lonnemann G, van der Meer JW, Cannon JG, Rogers TS, Klempner MS, Weber PC, et al. (1989) The effect of dietary supplementation with n-3 polyunsaturated fatty acids on the synthesis of interleukin-1 and tumor necrosis factor by mononuclear cells. N Engl J Med 320 (5):265-271. doi:10.1056/NEJM198902023200501

Eriksson EE, Xie X, Werr J, Thoren P, Lindbom L (2001) Direct viewing of atherosclerosis in vivo: plaque invasion by leukocytes is initiated by the endothelial selectins. FASEB J 15 (7):1149-1157

Foliaki S, Annesi-Maesano I, Tuuau-Potoi N, Waqatakirewa L, Cheng S, Douwes J, Pearce N (2008) Risk factors for symptoms of childhood asthma, allergic rhinoconjunctivitis and eczema in the Pacific: an ISAAC Phase III study. Int J Tuberc Lung Dis 12 (7):799-806

Gabbay E, Fisher AJ, Small T, Leonard AJ, Corris PA (1998) Exhaled single-breath nitric oxide measurements are reproducible, repeatable and reflect levels of nitric oxide found in the lower airways. Eur Respir J 11 (2):467-472

Gallai V, Sarchielli P, Trequattrini A, Franceschini M, Floridi A, Firenze C, Alberti A, Di Benedetto D, Stragliotto E (1995) Cytokine secretion and eicosanoid production in the peripheral blood mononuclear cells of MS patients undergoing dietary supplementation 
with n-3 polyunsaturated fatty acids. J Neuroimmunol 56 (2):143-153.

doi:016557289400140J [pii]

Galland L (2010) Diet and inflammation. Nutr Clin Pract 25 (6):634-640. doi:25/6/634 [pii]

Gibney MJ, Hunter B (1993) The effects of short- and long-term supplementation with fish oil on the incorporation of $n-3$ polyunsaturated fatty acids into cells of the immune system in healthy volunteers. Eur J Clin Nutr 47 (4):255-259

Hancox RJ, Poulton R, Greene JM, Filsell S, McLachlan CR, Rasmussen F, Taylor DR, Williams MJ, Williamson A, Sears MR (2007) Systemic inflammation and lung function in young adults. Thorax 62 (12):1064-1068. doi:thx.2006.076877 [pii]

Harris WS (2004) Fish oil supplementation: evidence for health benefits. Cleve Clin J Med 71 (3):208-210, 212, 215-208 passim

Juturu V (2008) Omega-3 fatty acids and the cardiometabolic syndrome. Journal of the cardiometabolic syndrome 3 (4):244-253. doi:10.1111/j.1559-4572.2008.00015.x

Kew S, Mesa MD, Tricon S, Buckley R, Minihane AM, Yaqoob P (2004) Effects of oils rich in eicosapentaenoic and docosahexaenoic acids on immune cell composition and function in healthy humans. Am J Clin Nutr 79 (4):674-681

Kinsella JE, Lokesh B, Broughton S, Whelan J (1990) Dietary polyunsaturated fatty acids and eicosanoids: potential effects on the modulation of inflammatory and immune cells: an overview. Nutrition 6 (1):24-44; discussion 59-62

Laerum BN, Wentzel-Larsen T, Gulsvik A, Omenaas E, Gislason T, Janson C, Svanes C (2007) Relationship of fish and cod oil intake with adult asthma. Clin Exp Allergy 37 (11):16161623. doi:CEA2821 [pii]

Lee TH, Hoover RL, Williams JD, Sperling RI, Ravalese J, 3rd, Spur BW, Robinson DR, Corey EJ, Lewis RA, Austen KF (1985) Effect of dietary enrichment with eicosapentaenoic and docosahexaenoic acids on in vitro neutrophil and monocyte leukotriene generation and neutrophil function. N Engl J Med 312 (19):1217-1224. doi:10.1056/NEJM198505093121903

Lewis RA, Austen KF, Soberman RJ (1990) Leukotrienes and other products of the 5lipoxygenase pathway. Biochemistry and relation to pathobiology in human diseases. N Engl J Med 323 (10):645-655. doi:10.1056/NEJM199009063231006

Libby P, Ridker PM, Maseri A (2002) Inflammation and atherosclerosis. Circulation 105 (9):1135-1143

Meydani SN, Lichtenstein AH, Cornwall S, Meydani M, Goldin BR, Rasmussen H, Dinarello CA, Schaefer EJ (1993) Immunologic effects of national cholesterol education panel step-2 diets with and without fish-derived N-3 fatty acid enrichment. J Clin Invest 92 (1):105-113. doi:10.1172/JCI116537

Mickleborough TD, Lindley MR, Ionescu AA, Fly AD (2006) Protective effect of fish oil supplementation on exercise-induced bronchoconstriction in asthma. Chest 129 (1):3949. doi:129/1/39 [pii] 
Mickleborough TD, Murray RL, Ionescu AA, Lindley MR (2003) Fish oil supplementation reduces severity of exercise-induced bronchoconstriction in elite athletes. Am J Respir Crit Care Med 168 (10):1181-1189. doi:10.1164/rccm.200303-373OC

Miyamoto S, Miyake Y, Sasaki S, Tanaka K, Ohya Y, Matsunaga I, Yoshida T, Oda H, Ishiko O, Hirota Y (2007) Fat and fish intake and asthma in Japanese women: baseline data from the Osaka Maternal and Child Health Study. Int J Tuberc Lung Dis 11 (1):103-109

Nagel G, Linseisen J (2005) Dietary intake of fatty acids, antioxidants and selected food groups and asthma in adults. Eur J Clin Nutr 59 (1):8-15. doi:10.1038/sj.ejcn.1602025

Nicholls SJ, Lundman P, Harmer JA, Cutri B, Griffiths KA, Rye KA, Barter PJ, Celermajer DS (2006) Consumption of saturated fat impairs the anti-inflammatory properties of highdensity lipoproteins and endothelial function. J Am Coll Cardiol 48 (4):715-720. doi:S0735-1097(06)01338-6 [pii]

Obata T, Nagakura T, Masaki T, Maekawa K, Yamashita K (1999) Eicosapentaenoic acid inhibits prostaglandin D2 generation by inhibiting cyclo-oxygenase-2 in cultured human mast cells. Clin Exp Allergy 29 (8):1129-1135. doi:cea604 [pii]

Patel S, Puranik R, Nakhla S, Lundman P, Stocker R, Wang XS, Lambert G, Rye KA, Barter PJ, Nicholls SJ, Celermajer DS (2009) Acute hypertriglyceridaemia in humans increases the triglyceride content and decreases the anti-inflammatory capacity of high density lipoproteins. Atherosclerosis 204 (2):424-428. doi:S0021-9150(08)00750-8 [pii]

Porsbjerg C, Lund TK, Pedersen L, Backer V (2009) Inflammatory subtypes in asthma are related to airway hyperresponsiveness to mannitol and exhaled NO. J Asthma 46 (6):606612. doi:913557390 [pii]

Rasmussen F, Mikkelsen D, Hancox RJ, Lambrechtsen J, Nybo M, Hansen HS, Siersted HC (2009) High-sensitive C-reactive protein is associated with reduced lung function in young adults. Eur Respir J 33 (2):382-388. doi:09031936.00040708 [pii]

Rosenkranz SK, Townsend DK, Steffens SE, Harms CA (2010) Effects of a high-fat meal on pulmonary function in healthy subjects. Eur J Appl Physiol 109 (3):499-506.

doi:10.1007/s00421-010-1390-1

Sadeghi S, Wallace FA, Calder PC (1999) Dietary lipids modify the cytokine response to bacterial lipopolysaccharide in mice. Immunology 96 (3):404-410. doi:imm701 [pii]

Schwartz J, Weiss ST (1994) The relationship of dietary fish intake to level of pulmonary function in the first National Health and Nutrition Survey (NHANES I). Eur Respir J 7 (10):1821-1824

Sherwood L (2001) Human physiology : from cells to systems. 4th edn. Brooks/Cole, Pacific Grove, Calif.

Simopoulos AP (2002) Omega-3 Fatty Acids in Inflammation and Autoimmune Diseases. J Am Coll Nutr 21 (6):495-505

Simopoulos AP (2008) The importance of the omega-6/omega-3 fatty acid ratio in cardiovascular disease and other chronic diseases. Exp Biol Med (Maywood) 233 (6):674-688. doi:0711-MR-311 [pii] 
Sperling RI, Benincaso AI, Knoell CT, Larkin JK, Austen KF, Robinson DR (1993) Dietary omega-3 polyunsaturated fatty acids inhibit phosphoinositide formation and chemotaxis in neutrophils. J Clin Invest 91 (2):651-660. doi:10.1172/JCI116245

Tecklenburg-Lund S, Mickleborough TD, Turner LA, Fly AD, Stager JM, Montgomery GS (2010) Randomized controlled trial of fish oil and montelukast and their combination on airway inflammation and hyperpnea-induced bronchoconstriction. PloS one 5 (10):e13487. doi:10.1371/journal.pone.0013487

van Oostrom AJ, Rabelink TJ, Verseyden C, Sijmonsma TP, Plokker HW, De Jaegere PP, Cabezas MC (2004) Activation of leukocytes by postprandial lipemia in healthy volunteers. Atherosclerosis 177 (1):175-182. doi:S0021-9150(04)00374-0 [pii]

van Oostrom AJ, Sijmonsma TP, Verseyden C, Jansen EH, de Koning EJ, Rabelink TJ, Castro Cabezas M (2003) Postprandial recruitment of neutrophils may contribute to endothelial dysfunction. J Lipid Res 44 (3):576-583. doi:10.1194/jlr.M200419-JLR200

Whelan J, Rust C (2006) Innovative dietary sources of n-3 fatty acids. Annu Rev Nutr 26:75103. doi:10.1146/annurev.nutr.25.050304.092605 
Table 1 Baseline subject characteristics

\begin{tabular}{|c|c|c|}
\hline & Placebo condition & Fish oil condition \\
\hline Age, years & $22 \pm 2$ & $23 \pm 3$ \\
\hline Stature, $\mathrm{cm}$ & $179 \pm 7$ & $176 \pm 8$ \\
\hline Body mass, kg & $78.3 \pm 9.44$ & $82.7 \pm 11.4$ \\
\hline \multicolumn{3}{|l|}{ Pulmonary function } \\
\hline eNO, ppb & $20.2 \pm 10.7$ & $14.8 \pm 5.78$ \\
\hline $\mathrm{PEF}, 1 \mathrm{~s}^{-1}$ & $9.35 \pm 2.79$ & $7.93 \pm 1.63$ \\
\hline FEF $25-75,1 \mathrm{~s}^{-1}$ & $4.59 \pm 0.88$ & $3.64 \pm 0.69 *$ \\
\hline FEV1, 1 & $4.45 \pm 0.69$ & $4.05 \pm 0.46$ \\
\hline $\mathrm{FVC}, 1$ & $5.39 \pm 0.78$ & $5.26 \pm 0.91$ \\
\hline \multicolumn{3}{|c|}{ Impulse oscillometry } \\
\hline $\mathrm{Z} 5, \mathrm{kPa} \mathrm{l}^{-1} \mathrm{~s}^{-1}$ & $0.33 \pm 0.12$ & $0.36 \pm 0.06$ \\
\hline $\mathrm{R} 5, \mathrm{kPa} \mathrm{l}^{-1} \mathrm{~s}^{-1}$ & $0.31 \pm 0.12$ & $0.34 \pm 0.06$ \\
\hline $\mathrm{R} 20, \mathrm{kPa} \mathrm{I}^{-1} \mathrm{~s}^{-1}$ & $0.27 \pm 0.08$ & $0.27 \pm 0.06$ \\
\hline $\mathrm{X} 5, \mathrm{kPa}^{-1} \mathrm{~s}^{-1}$ & $-0.10 \pm 0.04$ & $-0.11 \pm 0.02$ \\
\hline Resonance freq & $11.4 \pm 3.30$ & $12.4 \pm 3.97$ \\
\hline \multicolumn{3}{|l|}{ Blood lipids } \\
\hline $\mathrm{TRG}, \mathrm{mg} \mathrm{dl}^{-1}$ & $76.3 \pm 40.6$ & $119.8 \pm 65.7$ \\
\hline $\mathrm{TC}, \mathrm{mg} \mathrm{dl}^{-1}$ & $156 \pm 22.2$ & $177 \pm 27.3$ \\
\hline
\end{tabular}

Values are mean $\pm \mathrm{SD}$

eNO exhaled nitric oxide, PEF peak expiratory flow, FEV25-75 forced expiratory flow between 25 and $75 \%, F E V 1$ forced expiratory volume in $1 \mathrm{~s}, F V C$ forced vital capacity, FEVI/FVC ratio of forced expiratory volume in $1 \mathrm{~s}$ to forced vital capacity, Z5 total respiratory impedance, $R 5 \& R 20$ resistive component of respiratory impedance at 5 and $20 \mathrm{~Hz}$, respectively, $X 5$ reactive component of respiratory impedance at $5 \mathrm{~Hz}, T R G$ triglycerides, $T C$ total cholesterol

* Significantly different from Placebo $(p<0.05)$ 
Table 2 Pulmonary function tests

\begin{tabular}{|c|c|c|c|c|}
\hline & \multicolumn{2}{|l|}{ Pre-HFM } & \multicolumn{2}{|l|}{ Post-HFM } \\
\hline & Placebo & Fish oil & Placebo & Fish oil \\
\hline \multicolumn{5}{|l|}{ Pulmonary function } \\
\hline eNO, ppb & $18.2 \pm 10.0$ & $16.4 \pm 8.07$ & $22.0 \pm 11.5^{*}$ & $15.7 \pm 7.73$ \\
\hline $\mathrm{PEF}, 1 \mathrm{~s}^{-1}$ & $9.25 \pm 1.01$ & $8.23 \pm 1.53$ & $9.04 \pm 1.41$ & $8.81 \pm 2.55$ \\
\hline FEF $25-75,1 \mathrm{~s}^{-1}$ & $5.50 \pm 3.28$ & $3.87 \pm 1.10$ & $4.39 \pm 0.96$ & $3.78 \pm 0.89$ \\
\hline FEV1, 1 & $4.45 \pm 0.63$ & $4.03 \pm 0.64$ & $4.35 \pm 0.61$ & $4.03 \pm 0.54$ \\
\hline FVC, 1 & $5.43 \pm 0.63$ & $5.11 \pm 0.84$ & $5.31 \pm 0.66$ & $5.22 \pm 1.11$ \\
\hline \multicolumn{5}{|c|}{ Impulse oscillometry } \\
\hline $\mathrm{Z} 5, \mathrm{kPa} \mathrm{l}^{-1} \mathrm{~s}^{-1}$ & $0.32 \pm 0.07$ & $0.39 \pm 0.16$ & $0.23 \pm 0.08$ & $0.37 \pm 0.12$ \\
\hline $\mathrm{R} 5, \mathrm{kPa} \mathrm{l}^{-1} \mathrm{~s}^{-1}$ & $0.31 \pm 0.07$ & $0.37 \pm 0.15$ & $0.28 \pm 0.07$ & $0.34 \pm 0.10$ \\
\hline $\mathrm{R} 20, \mathrm{kPa} \mathrm{l}^{-1} \mathrm{~s}^{-1}$ & $0.26 \pm 0.05$ & $0.29 \pm 0.08$ & $0.24 \pm 0.06$ & $0.26 \pm 0.07$ \\
\hline $\mathrm{X} 5, \mathrm{kPa}^{-1} \mathrm{~s}^{-1}$ & $-0.09 \pm 0.02$ & $-0.12 \pm 0.07$ & $-0.06 \pm 0.08$ & $-0.13 \pm 0.06$ \\
\hline Resonance freq & $10.3 \pm 2.37$ & $12.6 \pm 4.66$ & $9.93 \pm 2.16$ & $13.0 \pm 4.87$ \\
\hline \multicolumn{5}{|l|}{ Blood lipids } \\
\hline $\mathrm{TRG}, \mathrm{mg} \mathrm{dl}^{-1}$ & $74.9 \pm 32.5$ & $85.0 \pm 27.6$ & $119 \pm 44.4^{*}$ & $165 \pm 29.2 *$ \\
\hline $\mathrm{TC}, \mathrm{mg} \mathrm{dl}^{-1}$ & $162 \pm 25.4$ & $173 \pm 43.7$ & $162 \pm 28.5$ & $174 \pm 58.1$ \\
\hline
\end{tabular}

Values are mean $\pm \mathrm{SD}$

Significantly different from Placebo $(p<0.05)$

eNO exhaled nitric oxide, $P E F$ peak expiratory flow, FEV25-75 forced expiratory flow between 25 and $75 \%, F E V 1$ forced expiratory volume in $1 \mathrm{~s}, F V C$ forced vital capacity, FEV1/FVC ratio of forced expiratory volume in $1 \mathrm{~s}$ to forced vital capacity, Z5 total respiratory impedance, $R 5$ \& $R 20$ resistive component of respiratory impedance at 5 and $20 \mathrm{~Hz}$, respectively, $X 5$ reactive component of respiratory impedance at $5 \mathrm{~Hz}, T R G$ triglycerides, $T C$ total cholesterol

* Significantly different from Pre-HFM $(p<0.05)$ 

Figure 1
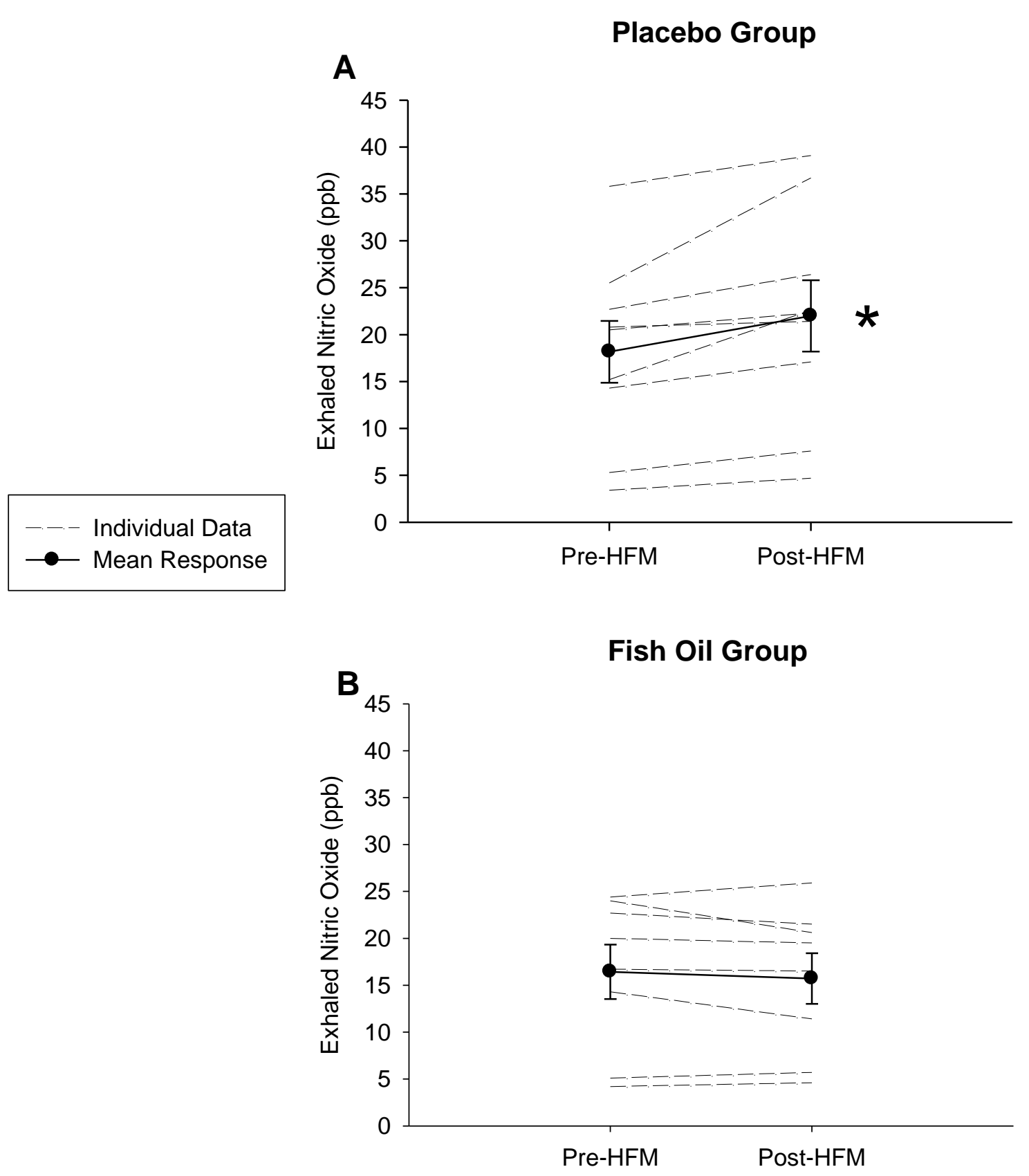

Fig. 1 Absolute changes in fractional exhaled nitric oxide pre- and post-HFM in placebo (a) and supplement group (b). Dashed lines represent individual data and filled circles respresent the group mean. Factional exhaled nitric oxide (airway inflammation) increased $\sim 4 \mathrm{ppb}$ in the placebo group after HFM vs. -1 ppb in the fish oil group. Asterisks significantly different than pre-HFM $(p<$ 0.05). Data presented as mean $\pm \mathrm{SE}$ 
Figure 2

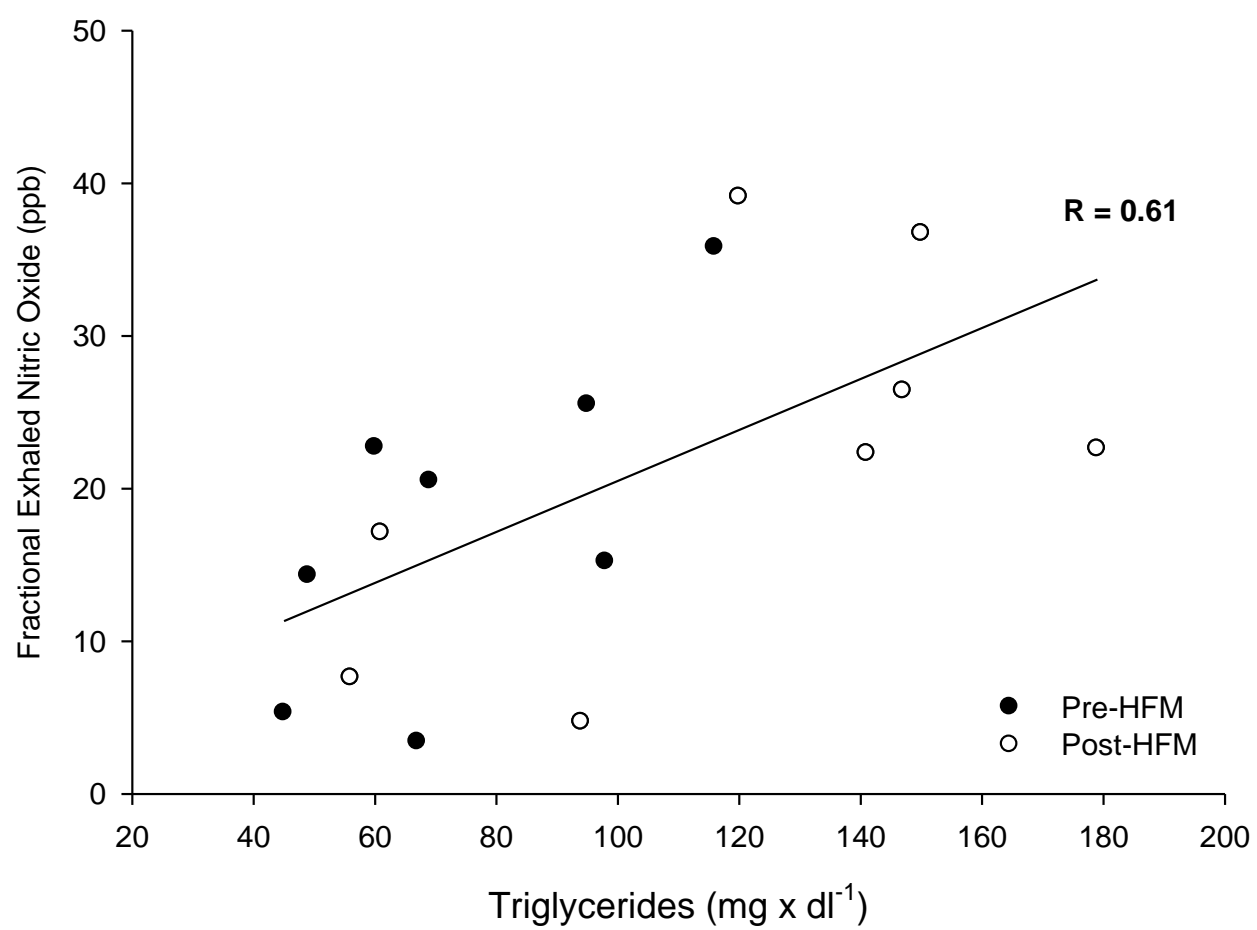

Fig. 2 Relationship between blood triglycerides and fractional exhaled nitric oxide pre and post-HFM $(p<0.05)$ 